\title{
The Tensile Performance of r-PET Bottle String: Effects of Different String Sizes and Cutting Axes
}

\author{
Khairani Nasir,"*, Azrin Hani Abdul Rashid', Nurul Atikah Abd. Razak', Muhammad Farid Shaari', \\ Mohd Nazrul Roslan', Shazarel Shamsudin², Mohd Shukri Ansar³, Siti Nor Hawanis Husain', \\ Syafiqah Dzulkefli ${ }^{1}$, Noraini Marsi ${ }^{1}$ \\ ${ }^{1}$ Faculty of Engineering Technology, Universiti Tun Hussein Onn Malaysia, Malaysia \\ ${ }^{2}$ Department of Manufacturing and Industry Engineering, Universiti Tun Hussein Onn Malaysia, Malaysia \\ ${ }^{3}$ Faculty of Engineering, Universiti Technology Malaysia, Malaysia
}

Received July 29, 2019; Revised September 29, 2019; Accepted December 15, 2019

Copyright $\bigcirc 2019$ by authors, all rights reserved. Authors agree that this article remains permanently open access under the terms of the Creative Commons Attribution License 4.0 International License

\begin{abstract}
Recently, plastic waste has become one of the global issues which contributes to severe environmental pollution and threatens marine life as it takes a longer time to decompose. This study was aimed to protect the environment by recycling waste materials to reduce solid wastes. Recycled polyethylene terephthalate string was used in the study to identify tensile properties. The main aim of this research was to identify the tensile strength properties by investigating different string sizes for the r-PET bottle $(4 \mathrm{~mm}, 5 \mathrm{~mm}$, and $6 \mathrm{~mm})$ at different cutting axes (horizontal and vertical). According to ASTM D882-02, the tensile strength test was conducted with a load cell of $50 \mathrm{~N}$ and crosshead speed of $50 \mathrm{~mm} / \mathrm{min}$ at room temperature. To reduce the possibility of nuisance factors that will affect the result, five repetitive tests were carried out and Minitab R.18 software was used to analyse the obtained data. Results revealed that the $4 \mathrm{~mm}$ string in both cutting axes demonstrated the highest strength of tensile performance and modulus elasticity.
\end{abstract}

Keywords Cutting Axis, String Size, Recycled Polyethylene Terephthalate, Tensile Strength

\section{Introduction}

The plastic waste evolution has become a larger solid waste issue and is growing exponentially since its profitable development in the late 1950s. This is because of the growth from its remarkable qualities, such as it is easy to shape, low cost and mechanical resistance. It is estimated that $80 \%$ of marine litter comes from land [1,2]. This pollution mainly comes from household wastes, which is poorly recycled, dumped in landfills or uncontrolled. The waste is carried by wind, pushed by the rain into sewers, streams, rivers, and finally into the oceans. Furthermore, it may cause pollution to the environment. Most solid waste comes from plastics, plastic bottles and paper that lead to huge environmental problems when disposed. In 2008, plastic production in China amounted to an extent of up to more than 37 million tonnes [3]. The projected demand for PET packaging materials is predicted to reach up to 20 million tonnes by 2019 with a further annual increase by $4.6 \%$ [4]. With the expansion in production and improvement in plastic applications, large amounts of plastic waste have been generated. These waste products mainly came from packaging materials and agricultural wastes[5] which mainly consist of polyethylene (PE), polypropylene (PP), polystyrene (PS) [6] and polyvinyl chloride (PVC) [7].

Most plastics are non-biodegradable [8] but they are definitely durable and waste plastic bottles are the major reason for solid waste disposal. Polyethylene terephthalate (PET) is usually used for carbonated beverages as water bottles. The plastic bottle wastes are difficult to biodegrade and involve processes that are either for recycling or reuse [9]. Since plastic bottles are always used, they will give major effect to the environment when they are not properly recycled. Therefore, to overcome the problem that can affect the environment and sceneries, the plastic bottle wastes can be recycled in many ways according to the functions and uses.

PET bottle can be recycled in several ways, such as by chemical and mechanical recycling. In chemical recycling, PET bottles are decomposed into monomer that constitutes the PET polymer by using solvents like water, methanol (hereafter, abbreviated as $\mathrm{MeOH}$ ) or ethylene glycol (abbreviated as EG). The monomers are reused [10]. Mechanical recycling of plastic bottles is by turning them 
into strings. PET strings can be widely used in textile industries as it can produce a new form of yarn [11]. Meanwhile, the string can also be used as a composite material in the textile structure [11]. In composite industries, PET can be used as a composite reinforcement for certain purposes. To test the string strength, the tensile strength test is conducted. The diameter and the cutting axis of the string are important parameters that can affect the string strength performance.

\section{Materials and Methods}

In this study, DESA brand drinking mineral water was used as the main element. The bottle was cleaned from dirt and the label was removed. The bottles were accordingly categorised for the next process.

\subsection{String Fabrication}

The top and bottom parts of the r-PET bottle sample were cut by using a cutter device. The remaining part was used to make strings of various diameters, which were 4 $\mathrm{mm}, 5 \mathrm{~mm}$, and $6 \mathrm{~mm}$ with different cutting axes (horizontal and vertical).

\subsection{Tensile Testing}

Tensile test was carried out by using Llyod Instrument LR 30K Universal Testing Machine with a load cell of $500 \mathrm{~N}$ in accordance to the ASTM D888-02 standard. The gauge length section was $50 \mathrm{~mm}$ with different string diameters $(4 \mathrm{~mm}, 5 \mathrm{~mm}$, and $6 \mathrm{~mm}$ ). The samples with different cutting axes (vertical and horizontal) are shown in Fig. 1. They were also tested with crosshead speed of 50 $\mathrm{mm} / \mathrm{min}$. Ten repetition samples were taken from each string.

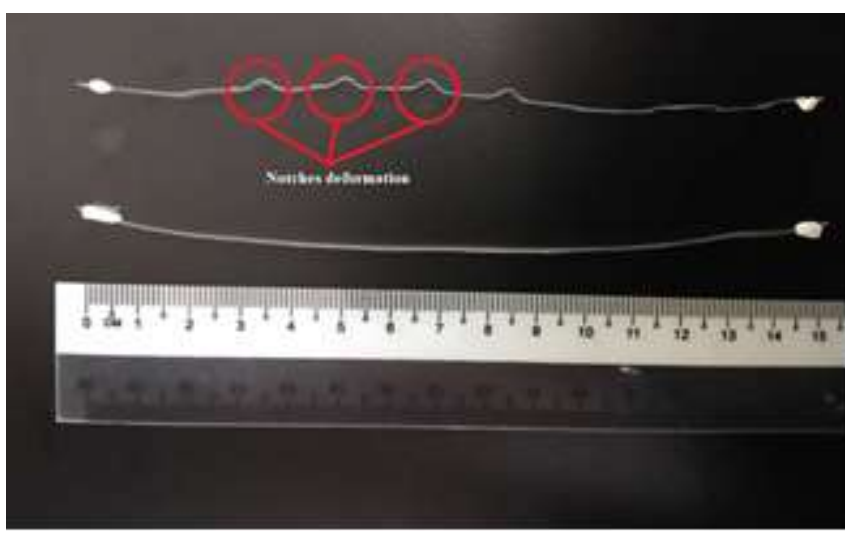

Figure 1. The r-PET string at different cutting axis (a) Vertical; (b) Horizontal

\subsection{Experimental Design}

A study that involves the effects of two or more factors in the factorial design is one of the most effective methods for experiments [12]. By using this powerful design of experiments (DOE) method, it will provide an efficient and systematic approach by involving all possible experimental trials. All study factors or parameters need to be identified and followed by the selection of the levels at which each factor will be examined in prior [12]. Two factors were identified in the research, which were the axis of the r-PET cutting bottle and the size of the r-PET string. There were two levels of cutting axes (horizontal and vertical) and three levels of r-PET string sizes (4 mm, $5 \mathrm{~mm}$ and $6 \mathrm{~mm}$ ). Therefore, the full factorial design with mixed levels was engaged. To avoid bias in the result, ten repetition tests were assigned and randomization was activated. Results of the study were statistically analysed by performing an analysis of variance (ANOVA) to evaluate the significance of the main and interaction factor effects for each response variable. P-value of less than 0.05 was considered significant [12]. To reduce the possibility of nuisance factors affecting the experiment, Minitab R.18 software was used.

\section{Result and Discussion}

The stress-strain curve is clearly illustrated in Fig. 2, whereby the r-PET can be categorised as a ductile material due to the plastic deformation at the strain rate of between 0.05 and above. The curve trend on the graph demonstrates an increase to the higher stress levels in both r-PET cutting axes (horizontal and vertical). By necking formation on the stress-strain curves exhibited the material strong irreversible plastic deformation and tend to continuous strain-hardening with the fracture strain of larger than 0.4. Due to the initial straightening of the notched deformations (Fig. 1) on r-PET, the stress-strain curve of the vertical axis illustrated a slight necking as compared to horizontal axis which contributed to a higher tensile strength and elongation [13].

Table 1 and Table 2 display the overall results obtained from tensile performance of the r-PET string at different cutting axes (horizontal and vertical) data. To avoid bias in results, five repetitions on each tensile characteristic sample were evaluated and randomization was activated to describe the tensile performance of the r-PET string. The presented low standard deviation values and the overall tabulated data show a good stability. The tables represent differences in tensile performance readings between two different cutting axes of r-PET string. The highest maximum stress was acquired from both cutting axes at string size of $4 \mathrm{~mm}$, which were $2.5721 \mathrm{GPa}$ (horizontal) and $3.5245 \mathrm{GPa}$ (vertical), respectively. 


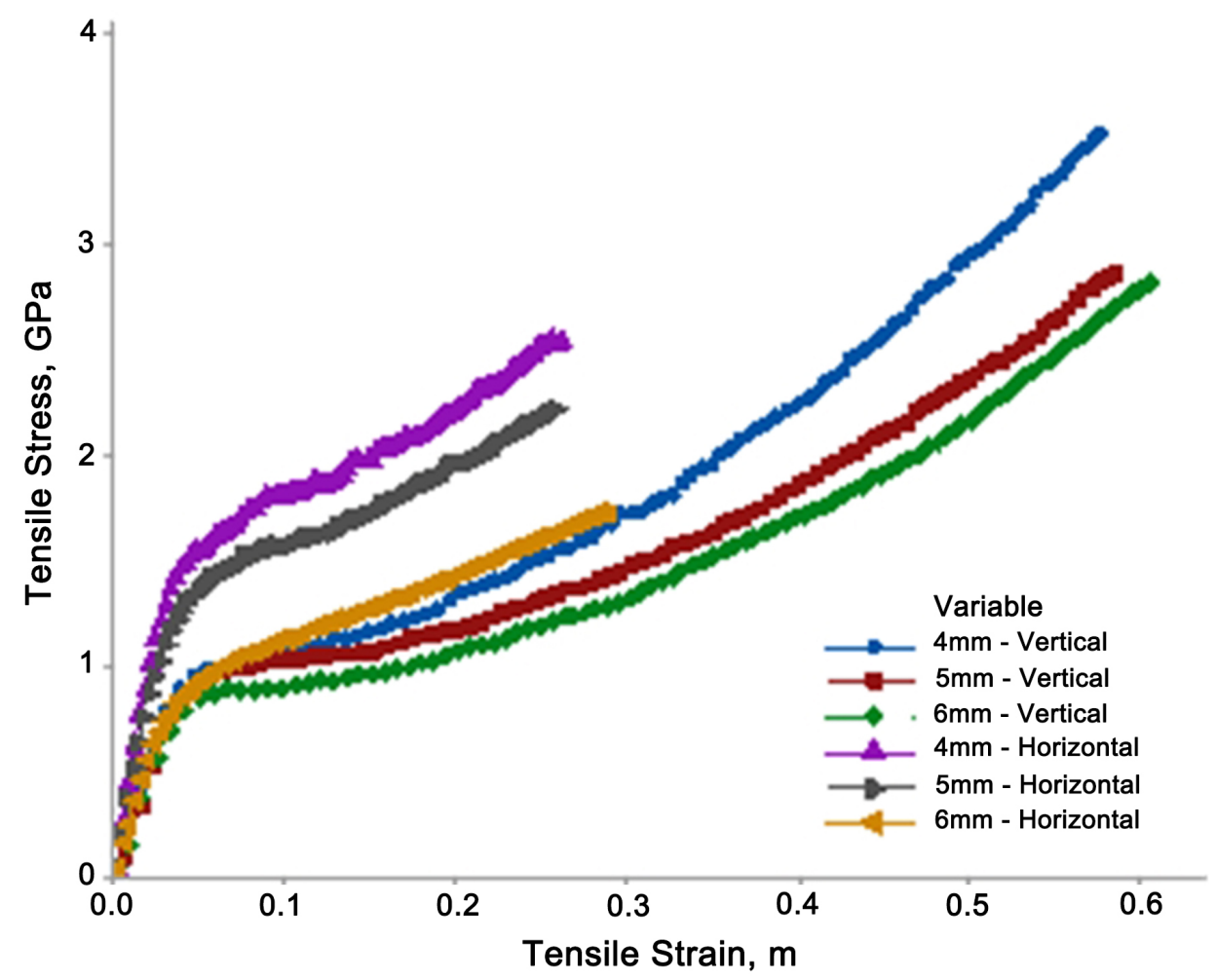

Figure 2. Tensile stress-strain curve of r-PET string

Table 1. Tensile test result of the r-PET string at horizontal cutting axis

\begin{tabular}{|c|c|c|c|}
\hline Sample & $\begin{array}{c}\text { Max Stress } \\
(\mathrm{GPa})\end{array}$ & Max Strain & $\begin{array}{c}\text { Modulus } \\
\text { Elasticity (GPa) }\end{array}$ \\
\hline $4 \mathrm{~mm}$ & 2.549 & 0.261 & 41.69 \\
\hline $5 \mathrm{~mm}$ & 2.218 & 0.259 & 35.204 \\
\hline $6 \mathrm{~mm}$ & 1.728 & 0.287 & 25.307 \\
\hline
\end{tabular}

Table 2. Tensile test result of the r-PET string at vertical cutting axis

\begin{tabular}{|c|c|c|c|}
\hline Sample & $\begin{array}{c}\text { Max Stress } \\
(\mathrm{GPa})\end{array}$ & Max Strain & $\begin{array}{c}\text { Modulus } \\
\text { Elasticity (GPa) }\end{array}$ \\
\hline $4 \mathrm{~mm}$ & 3.525 & 0.575 & 26.469 \\
\hline $5 \mathrm{~mm}$ & 2.858 & 0.584 & 21.858 \\
\hline $6 \mathrm{~mm}$ & 2.810 & 0.604 & 21.250 \\
\hline
\end{tabular}

However, the tensile strength value decreased with an increase in string size diameter of $5 \mathrm{~mm}$ and $6 \mathrm{~mm}$. As it can withstand the highest maximum breaking load, the optimum string size $(4 \mathrm{~mm})$ resulted in the best string size as compared with the other two different string sizes of r-PET. On the other hand, the modulus elasticity showed that the optimum size was higher than $5 \mathrm{~mm}$ and $6 \mathrm{~mm}$ due to stiffer material, as proven by Askeland et al., 2006 [14]. It can be concluded that the optimum r-PET string size in vertical has the highest string strength on the notching deformation presence on the r-PET string surface. Meanwhile, the optimum of r-PET string size in horizontal represented the good tensile performance properties on the flat surface of r-PET string without the presence of the notch deformation.

Table 3. ANOVA result for; (a) tensile strength; and (b) modulus elasticity

\begin{tabular}{|c|c|c|c|c|c|}
\hline Source & $D f$ & $S S$ & $M S$ & $\boldsymbol{F}$ & $p$ \\
\hline \multicolumn{6}{|c|}{ (a)Tensile Strength } \\
\hline Axis & 1 & 5.9155 & 5.9155 & 124.40 & 0.000 \\
\hline Size & 2 & 4.6108 & 2.3054 & 48.48 & 0.000 \\
\hline Axis*Size & 2 & 0.0344 & 0.0172 & 0.36 & 0.700 \\
\hline Error & 24 & 1.1412 & 0.0476 & & \\
\hline Total & 29 & 11.7020 & & & \\
\hline \multicolumn{6}{|c|}{ (b)Modulus Elasticity } \\
\hline Axis & 1 & 1632.6 & 1632.59 & 114.17 & 0.000 \\
\hline Size & 2 & 1191.1 & 595.57 & 41.65 & 0.000 \\
\hline Axis*Size & 2 & 363.3 & 181.65 & 12.70 & 0.000 \\
\hline Error & 24 & 343.2 & 14.30 & & \\
\hline Total & 29 & 3530.2 & & & \\
\hline
\end{tabular}

$D f$ : degree of freedom, $S S$ : sum of squares, $M S$ : mean swuare, $F$ : F-test, $p$ : $p$-Value

Note: The bold values indicates that the value is less than 0.05 which imply that the factors effect is presence and significant as mentioned in the respective article.

ANOVA results for tensile test of all samples are presented in Table 3(a). Tensile strength results indicated that the cutting axis and string size of r-PET were influenced by the tensile performance and it clearly showed that both factors had significant effects due to the 
lower $\mathrm{p}$-value $(\mathrm{p}<0.05)$. There was no interaction effects among the cutting axes with string size of r-PET because the p-value was bigger than 0.05 . The main effects average data plot for the r-PET string tensile strength is displayed in Fig. 3(a). The figure demonstrates that the vertical axis exhibits higher tensile strength due to the notch deformation on the surface of r-PET string. The horizontal axis illustrates the lowest tensile strength value. The minimum string size of $4 \mathrm{~mm}$ generated the highest tensile response value whereas the $5 \mathrm{~mm}$ and $6 \mathrm{~mm}$ string sizes exhibited almost the same value.

The ANOVA results in Table 3 (modulus elasticity) showed that the differences in cutting axes and cutting sizes were proved to significantly affect the r-PET string tensile performance $(\mathrm{p}<0.05)$. The analysis revealed the factor interaction presence with probability plot demonstration and $\mathrm{R}^{2}$ value of $87.04 \%$, and thus it indicated stable data distributions. Fig. 3(b) and Fig. 4 display the main effect plots and the interaction plots modulus elasticity of mean data. Higher modulus elasticity occurs on horizontal cutting axis due to stiffer material. It was proven from previous research that a stiffer material will affect the higher if the elastic modulus [14]. Differences in r-PET string size showed that the optimum size $(4 \mathrm{~mm})$ displayed the highest modulus elasticity. The interaction obtained that the optimum size of r-PET string on horizontal cutting exhibited better modulus elasticity, whereas the increase in modulus elasticity was proved to be affected by the decrease in string size [15].

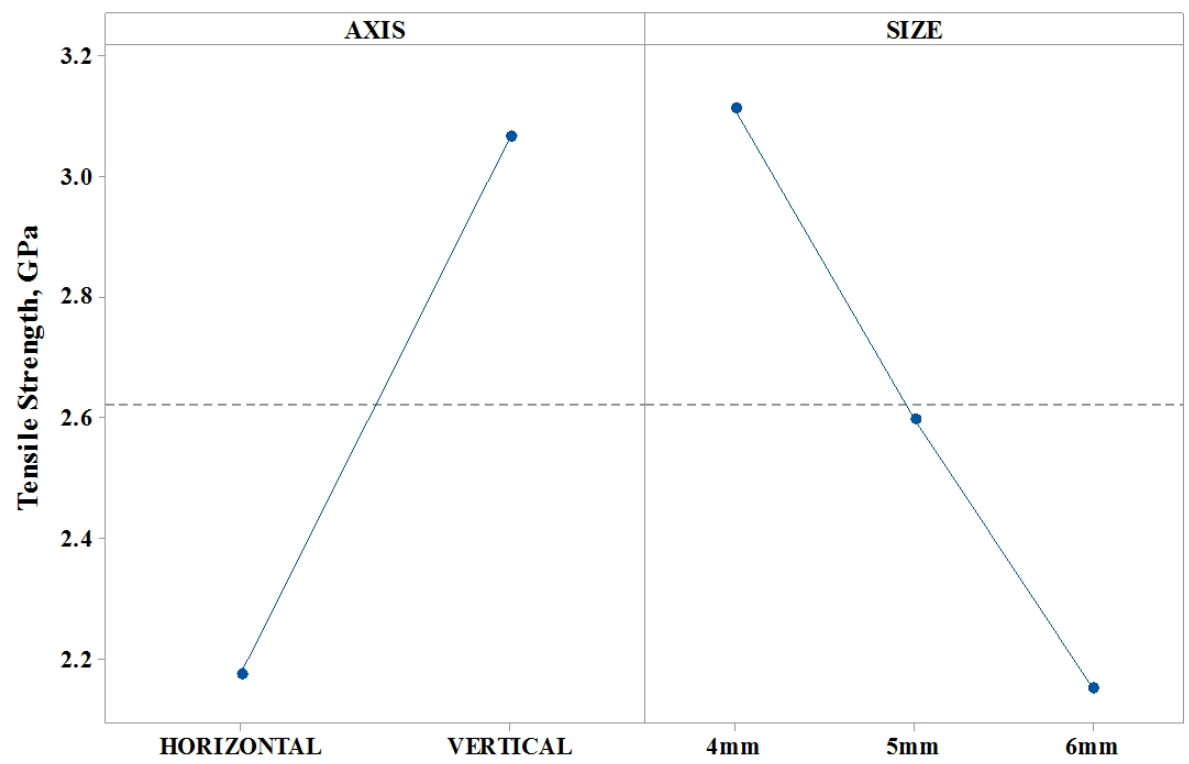

(a)

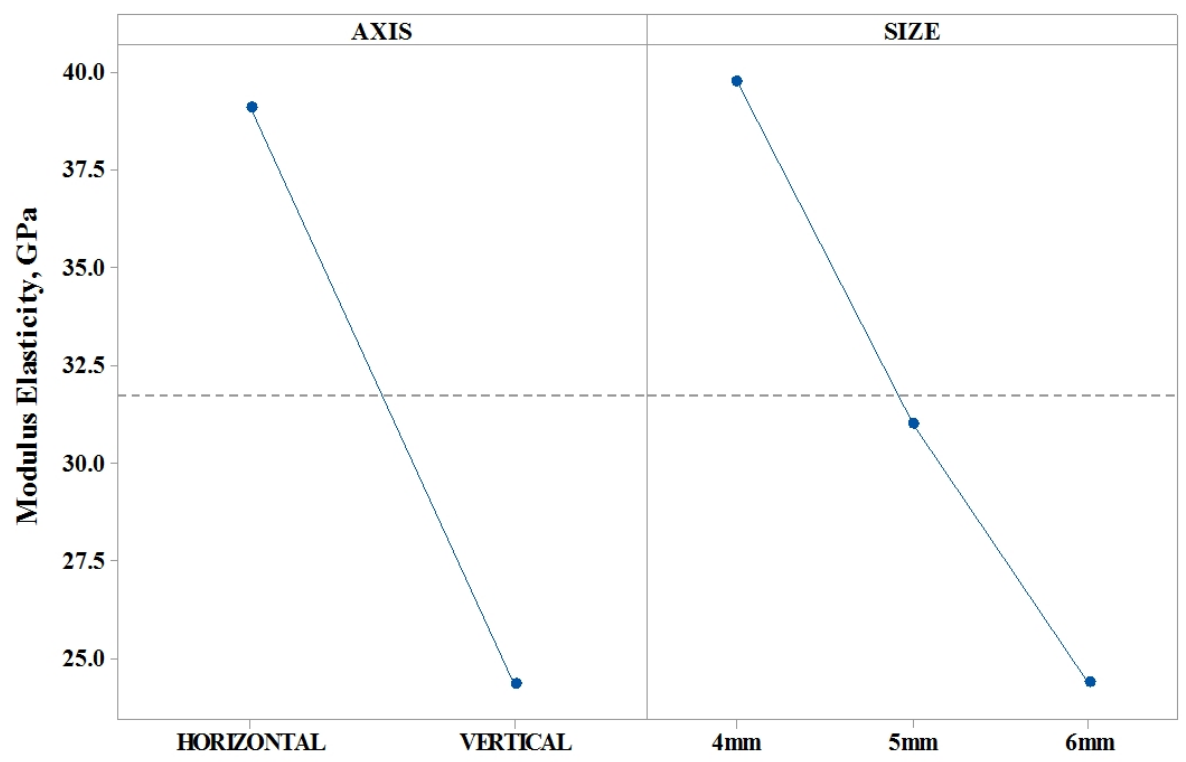

(b)

Figure 3. Main effects plot for (a) Tensile strength; and (b) Modulus elasticity 


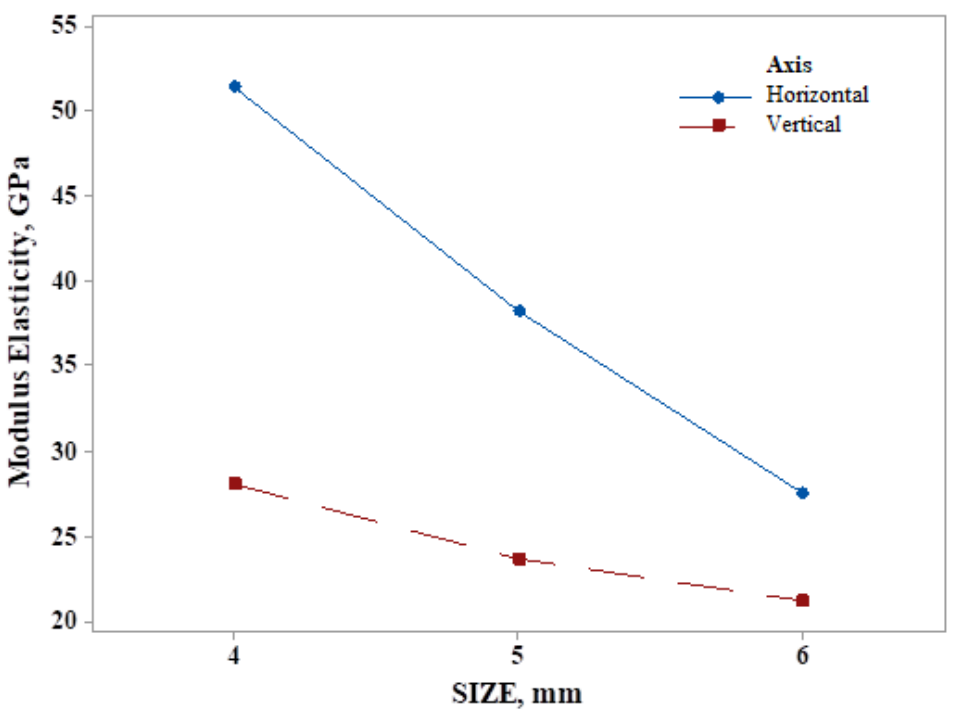

Figure 4. Interaction plot for modulus elasticity

\section{Conclusions}

From the study, the $4 \mathrm{~mm}$ r-PET string size on vertical cutting axis has the highest tensile strength. Based on results, the following specific conclusions were drawn:

1) Vertical cutting axis with the optimum r-PET string size leads to the tensile performance due to the lowest $\mathrm{p}$-value.

2) The r-PET cutting axis and string size exhibit a significant effect on the modulus elasticity due to the stiffer materials.

3) The optimum r-PET string size affects the higher modulus elasticity.

4) On the other hand, the horizontal cutting axis also reveals better modulus elasticity.

\section{Acknowledgements}

The researchers would like to thank Universiti Tun Hussein Onn Malaysia for providing the Geran Penyelidikan Pasca-Siswazah (GPPS) Vot H064 research grant, supported by the Ministry of Education Malaysia under the Fundamental Research Grant Scheme (FRGS) Vot K083 that has made this work possible.

\section{REFERENCES}

11 J. R. Jambeck, R. Geyer, C. Wilcox, T. R. Siegler, M. Perryman, A. Andrady, R. Narayan, K. L. Law. Plastic Waste Inputs from Land into the Ocean. Science, 347, 6223, 768-771, 2015.

|2| R. Geyer, J. R. Jambeck, K. L. Law. Production, Use, and Fate of All Plastics Ever Made, Sci. Adv. 3, 7, el700782, 2017.
|3| T. Chui, K. Song, S. Zhang. Research on Utilizing Recycled Plastic to Make Environment-Friendly Plywood. For Stud. China, 12(4), 218-222, 2010.

|4| E Sariogle, H. K. Kaynak. PET Bottle Recycling For Sustainable Textiles, Polyester. Production, Characterization and Innovative Applications. Nuhan Onar Camlibel IntechOpen, Online available from https://www.i ntechopen.com/books/polyester-production-characterizatio $\mathrm{n}$-and-innovative-applications/pet-bottle-recycling-for-sust ainable-textiles

|5| H. Zhang, X. F. Xiao, Y. F. Rao. Discussion on Prevention and Management "White Pollution". Jiangsu Environment Science Technology, 13(4), 45-46, 2000.

|6| Z. Y. Sun. The Current Situation and Development Trends of Recycled Plastic Food Packaging, China Packaging Industries, 8, 45-48, 2000.

$|7|$ M. T. Dang. The Progress in the "White Pollution" Controlling. J. Weinan Teachers Coll (Social Sciences), 14(2), 62-64, 1999.

$|\not|$ F Felle. Twenty Years Of PET Bottle To Bottle Recycling - An Overview. Resources, Conservation and Recycling, 55(11), 865-875, 2011.

|이 P. G. Prabhu, C. A. Kumar, R. Pandiyaraj, P. Rajesh, L. S. Kumar. Study on Utilization of Waste PET Bottle Fiber in Concrete. IMPACT: International Journal of Research in Engineering \& Technology, 2, 5, 233-240, 2014.

|10| T. Nakao, T. Chikatsune, M. Nakashima, M. Suzuki, H. Nagano. US Patent No. 7462649. Washington DC. Us Patent and Trademark Office.

111| S. H. Park, S. H. Kim. Poly (ethylene Terephthalate) Recycling for High Value Added Textiles. Fashion and Textiles, 1, 1, 2014.

|12| D. C. Montgomery. Design and Analysis of Experiments. 7th Ed. New York, Ny: John Wiley \& Sons, Inc, 2017.

|13|R. P. Borg, O. Baldacchino, L. Ferrara. Early Age Performance and Mechanical Characteristics of Recycled 
PET Fibre Reinforced Concrete. Construction and Building Materials, 108, 29-47, 2016.

|14| D. R. Askeland, P. P. Phule. The Science and Engineering of Material. 5th Ed. Thompson, Toronto, Canada, 183-223, 2006.

|15| D. Ahmad, K. Patra. Effect of Sample Size and Strain Rate on Uniaxial Tensile Behavior of Dielectric Elastomer. Indian Conference on Applied Mechanics IIT Delhi, 2015. 